\title{
Opinion \\ Case vignettes on life span approach to diagnosis of specific learning disability in india
}

Volume 8 Issue I - 2017

\section{Opinion}

The official recognition of Specific Learning Disability (SLD) through a nation-wide legislation is beginning-to-happen in the country. Apart from offering a tentative definition borrowed from the west, the enactment gives no description for identification or certification of affected children. Hence, it is likely that many non-core attributes may be mistaken as part of the condition. ${ }^{1}$ As it appears, the diagnosis is to be carried out by exclusion than by using inclusion characteristics. Further, the prevailing educational scenario in the country is that more than half of the child population is first generation learners, lack environmental opportunities, have poor school infrastructure, lack adequate health or nutritional status, use multiple languages between home and school, and follow many streams of syllabus or medium of instruction. All this obviates the adoption of available western models for defining this condition. ${ }^{2}$ The problem of defining SLD is

not unique to India. Its nomenclature and definitions have changed regularly owing to government involvement and legislation across many nations. For example, New Zealand ${ }^{3,4}$ and Canadian ${ }^{5}$ definitions of learning disability follow the US traditions. The British definition of learning disability is an equivalent of intellectual disability. ${ }^{6}$ The term 'learning difficulty' includes people with 'specific learning difficulties' like 'dyslexia' without any significant general impairment of intelligence in Australia and United Kingdom. ${ }^{7}$ Moreover, it is pointed that the official definition of the condition at least in India, is largely based on findings and observations of children studying in English medium schools'. ${ }^{8}$ Against this rather evolving scenario, a life span approach to diagnosis of SLD is often missed. Most text-books and official classifications expound cross sectional approach of ticking from a list of behavioral attributes in a child that either match or do not match among what is presumed as the defining characteristics of SLD. Although this perspective seems methodical, intra-individual progression and transformation by age as it happen for SLD get overlooked. ${ }^{9,10}$ Even if considered, it becomes piecemeal attempt to view affected children in their preschool and school years, adolescence and adults separately. ${ }^{11,12}$ A life span perspective on SLD typically draws attention to different dimensions of presenting complaints, causes, characteristics, and consequences in given instances of such affected children. Given below are illustrative caselets of children at-risk or those affected by prodromal symptoms during preschool years (Caselet \#1), those with active clinical characteristics presented as academic delays during their primary and secondary school years (Caselet \#2), before culminating into a full blown SLD by high school (Caselet \#3). There is also a stage beyond adolescence when the individuals with SLD have to manage the residual vestige of the condition all through their lives (Caselet \#4).

\section{Caselet \# I}

Raju, aged 5, student of UKG, uses 2-4 word level utterances with routine acquaintance in familiar situations. He lacks spontaneous narrative speech, and cannot convey messages across people or on

\author{
Venkatesan S \\ Department of Clinical Psychology, All India Institute of Speech \\ and Hearing, India
}

Correspondence: Venkatesan S, Department of Clinical Psychology, All India Institute of Speech and Hearing, Manasagangothri, Mysore, 570 006, Karnataka, India, Tel 91-082I2502142,Email psyconindia@gmail.com

Received: July 01, 2017 | Published: July 17, 2017

phone. He has difficulties in coloring on paper within a boundary, cannot button, tie knots, fold or tear paper along a crease, does not cup hands to hold water, fails to trace own palm on paper, does not light a candle or cut shapes using a pair of scissors. At the preschool, there were complaints that the child does not sit in one place to copy from blackboard or copy-write.

\section{Caselet \#2}

Rahul, aged 9, student of class four, cannot spell 3-4 letter words in English, lacks alphabet sound correspondence, or understanding of phonetic rules. He cannot rote count numbers beyond 100, cannot serial subtract 20-2, does not add single or 2-digit numbers, cannot differentiate big-small numbers or arrange them in ascendingdescending order. His grade equivalent score measured to be around UKG level.

\section{Caselet \#3}

Asha, 14year old pupil of class nine, presented as shy, timid, tearful, moody, aloof, and unwilling to go with class mates. She stammered, wet bed at night, and occasionally refused to go to school. Although measured as functioning at the level of above average intelligence, the grade discrepancy on achievement tests placed her at class three for reading, writing, spelling and arithmetic.

\section{Caselet \#4}

Anu, 2lyear old, was first seen as middle school pupil with academic delay, which was later diagnosed as SLD. Although fluent in 4-5 spoken languages, including a foreign one, she continued to show difficulties in reading, writing and/or spelling across all of them. She worked as free-lance interpreter with a local tourism agency and won appreciation for the oral fluency in the many languages.

Although the caselets are intended to be illustrative, they highlight what students with SLD can do as well as cannot do across age levels. The emphasis on teaching at higher levels of formal academics at 
home and school despite the presence of unachieved lower academic skill appear to place these students at a perpetual disadvantage, thereby leading them to acquire contemporary emotional-behavioral problems like inability to sustain attention-concentration, showing poor compliance for and difficulties in writing, or being slow to expected speed, with general disinterest mainly for school, and academic related activities. These observations may sometimes lead to the mistaken impression of the student having attention-deficit disorder, opposition defiant disorder, and/or conduct disturbances and have even led to prescription of medicines with no respite. Meanwhile, their grades also dip year after year with the school authorities threatening expulsion if the situation did not improve. School change is tried with no benefit. Surprisingly, proficiency is often reported in the student for several non-academic engagements, such as, handling electronic gadgets for hours together with surprisingly no breaks in attention or concentration. Parents regrettably attribute the root cause of all these problems as owing to their own faulty caregiver practices. In sum, while there is still a long way to go for framing a standard definition of SLD as applicable to the country, such students meanwhile need early identification, individualized, learner paced, play-cum-activity based instruction at younger ages. This may have to be replaced with compensatory strategies if they are older wherein their assets are exploited rather than denigrating or depreciating their deficits.

\section{Acknowledgments}

None.

\section{Conflicts of interest}

Author declares there are no conflicts of interest.

\section{Funding}

None.

\section{References}

1. Venkatesan S. Analysis of attributes in the official definitions for learning disability. The International Journal of Indian Psychology. 2017;4(2):46-57.
2. Venkatesan S. The enigma of diagnosis by exclusion: a field study on children frequently mistaken for learning disability in India. Disabilities and Impairments. 2012;26(1):5-16.

3. Learning Disability Association of New Zealand. Specific learning disability,New Zealand. 2016.

4. Speld NZ. Specific learning disability, New Zealand. 2016.

5. Learning Disabilities Association of Canada (LDAC). Definition of learning disabilities, Canada. 2015.

6. Emerson E, Heslop P. A working definition of learning disabilities. Improving Health and Lives, Learning Disability Observatory, USA. 2010 .

7. Graham L, Bailey J. Learning disabilities and difficulties: an Australian conspectus-introduction to the special series. J Learn Disabil. 2007;40(5):386-391.

8. Karanth P. Language and learning disability or language learning disability. In: Karanth P \& Rozario J (Eds.), Learning disabilities in India: Willing the mind to learn. Sage Publications, New Delhi, India. 2003.

9. Grant G, Ramcharan P, Flynn M, et al. Learning disability: a life cycle approach. Open University Press and McGraw Hill Education, England, UK. 2010. p.1-536.

10. Thapa K, Van Der Aalsvoort GM, Pandey J. Perspectives on learning disabilities in India: Current Practices and Prospects. Sage Publications, New Delhi, India. 2008. p.33-35.

11. Holland AJ. Ageing and learning disability. British Journal of Psychiatry. 2000;176(1):26-31.

12. Polloway EA, Smith JD, Patton JR. Learning disabilities: an adult development perspective. Learning Disability Quarterly. 1984;7(2):179-186. 